\title{
Tutor facilitation in A PBL writing classroom through face-to- face group interactions
}

\author{
Muhammad Mukhtar Aliyu ${ }^{1^{*}}$, Mei Fung Yong ${ }^{2^{*}}$ \\ ${ }^{1}$ Bauchi State University, Gadau, Nigeria, ${ }^{2}$ Universiti Putra Malaysia, Malaysia \\ ${ }^{1}$ mamukhtar@basug.edu.ng; ${ }^{2}$ yong@ @upm.edu.my \\ * corresponding author
}

\section{ARTICLE INFO}

Article history

Received : April 20, 2019

Revised : May 7, 2019

Accepted : May 28, 2019

Keywords

ESL writing

Face-to-face

PBL

Tutor facilitation

\section{ABSTRACT}

This study reveals the strategies used by tutors in facilitating students' writing process in a problem-based learning environment (PBL) through face-to-face group interactions. is one of the social media platforms found interesting and used by most of the students to interact with one another in and out of the school environment. It is used to provide social support to the students. An intact class of 18 second-year students in an English Composition course in Nigeria was selected in the study. The students were provided with a guide by tutors during the PBL writing process. Two tutors facilitated the students' writing process in the PBL process. Tutor facilitation is one of the major components that facilitate meaningful learning in PBL. This is because, without proper guidance, students would end up in unfocused learning. Data were obtained through audio- and video-recording of students' face-to-face interactions chats. The findings showed that the PBL tutors used various strategies to facilitate the participants' writing such as open-ended questioning, metacognitive questioning, pushing students for an explanation, revoicing, summarizing, and generating/evaluating hypotheses. The support provided by the tutors helped the students to improve their writing. The findings of the study suggest some ways for teachers to improve students writing skills.

This is an open access article under the CC-BY-SA license.

\section{Introduction}

Writing is the most challenging language skill to be acquired by students not only in second (L2) or foreign language (FL) but also in the first language (L1). Various studies have been conducted on how to improve students' writing skills. Some scholars suggested that writing is a cognitive and social process where students need to be helped during the process. For example, teachers are expected to give cognitive and social supports to students to allow them to improve their writing.

PBL is one of the learning approaches that recognise the importance of tutor facilitation in the learning process. Tutor facilitation is one of the major components that facilitate meaningful learning in PBL. This is because, without proper guidance, students would end up in unfocused learning (Tan, 2004). In PBL, tutor facilitation is based on Vygotsky's theory of cognitive development which views a learner as the one that can develop a more systematic, logical, and rational concept from their dialogue with a skilled helper which can be a teacher or a peer who is 
more skilled in the subject (Santrock, 2009; Vygotsky, 1978). This would allow the learner to get to the zone of proximal development (ZPD) which is the next level learners can achieve potentially with the assistance of a more capable person or peer (Raymond, 2000).

To give an overview of the PBL approach, it is a learner-centred approach where students take major responsibility for their learning. Contents of the curriculum are to students in the form of an ill-structured problem, which is related to their real-life situations and has multiple and not straightforward answers. Students are assigned to smaller groups and asked to collaboratively discuss the problems and propose viable solutions. The students decide and discover for themselves what they will learn and how they will learn it. From the interaction, the students identify issues they need to find out more information about. They share the issues among them and conduct selfdirected learning. In the interactions, tutor(s) support or facilitate the students' learning through questioning and probing. This results to the students' development of learning output alongside their critical thinking and other skills (Mardziah H. Abdullah \& Tan, 2008; Bridges \& Hallinger, 1995; Savin-Baden, 2000; Tan et al., 2000; Tan 2004).

Thus, tutor facilitation is one of the most important components for the successful implementation of PBL. It guides the students on how to interact and discuss the ill-structured problem in every step of PBL. For example, at the beginning of PBL, tutor facilitation may help them activate prior knowledge and identify key elements from the ill-structured problem. In addition, tutor facilitation may help the students to facilitate the analysis of the ill-structured problem and assist them to identify learning issues. Furthermore, when the students are engaged in self-directed learning, tutor facilitation may help them perform more goal-oriented information searching, improving the effectiveness of their exploratory learning. The same thing when students are at the phase of generating ideas, tutor facilitation may facilitate their evaluation of possible solutions to the ill-structured problem ( $\mathrm{Su}, 2007)$. To summarise the roles of the tutor(s) in the facilitation process, Woods (2002) suggested that at the beginning of a PBL process tutors should ensure that students approach the ill-structured problem appropriately. This could be achieved through challenging the students' assumptions, to ensure that they reflect on and justify their assertions. At the end of a PBL session, tutors should close it by enabling the students to reflect on the dynamics of the group session and what they learned. Therefore, tutor facilitation should be designed to encourage learners to think and work independently until getting to a problem solution. Through this, the students can work towards their ZPD.

Studies have examined strategies tutors should use to effectively facilitate students' learning. For instance, in other fields of study such as medicine where PBL first evolved, Hmelo-Silver and Barrows, (2006) have identified some strategies that can be employed by tutors, depending on the goals, to facilitate students' learning in the PBL process. These include open-ended questioning, metacognitive questioning, pushing students for an explanation, revoicing, summarizing, and generating/evaluating hypotheses, among others. Hmelo-Silver and Barrows, (2006) identified two goals: (a) educational goals which are what the students are expected to learn and (b) performance goals which are behaviours the tutors want to encourage (in support of the educational goals). Though Hmelo-Silver and Barrows' (2006) study is in the context of medical science, the goals could be applied in this study as they are subject general except the first educational goals explain disease processes responsible for a patient's symptoms and signs and describe what interventions can be undertaken' which is subject specific. However, it could be easily modified and applied in the current study.

Therefore, in this study, the tutors' goals for the participants were to be able to explain possible causes for the ill-structured problem given to them, effects of the problems, provide viable and plausible solutions and logically present the solutions in writing. In the process, the tutors wanted the participants to work collaboratively, employ effective reasoning skills to plan their writing through generating and organising information relevant to the ill-structured problems. Through these processes, the tutors wanted the participants to be aware of their knowledge limitations and meet their knowledge needs through self-directed learning. Finally, the tutors wanted the participants to be able to review and edit their writing. To achieve these goals, the tutors had to keep all the participants active and on track in the learning process, make their thinking and understanding apparent and encourage them to become independent in looking for direction and more information. 
In another study, Nguyen's (2013) identifies various kinds of supports students give to one another in making a collaborative oral presentation: workload sharing, pooling of ideas and resources, technology support, feedback for language development, support in answering the audience's questions and affective support. Although Nguyen's (2013) study is on collaborative oral presentation, it can be applied to this study because some of the supports are subject general. For example, the last item 'affective support for enduring task engagement, rapport, self-confidence and a sense of safety and success' is not subject specific. It could be used in collaborative learning in general.

Many studies have been conducted on PBL and revealed the positive impact of tutor facilitation in improving students' learning. However, in language classrooms, there is a lack of studies that look at tutor facilitation in PBL. For instance, Mardziah H. Abdullah and Tan (2008) stress the need for teachers to ensure that interactions among students during PBL activities (in ESL classrooms) are in English. This shows the need to examine how tutors facilitate students during the PBL writing processes. Therefore, the purpose of this study is to identify and examine the strategies are used by tutors in a PBL writing classroom.

\section{Research Questions}

To guide the study, the following research question is formulated:

How do tutors facilitate students' learning in the PBL writing process?

\section{Method}

\section{Participants of the Study}

The participants of the study comprised of an intact class of 18 second-year students in an English Composition course. The participants were of mixed-gender and their ages ranged from 2438 years old. They were assigned into three groups to carry out the PBL activities with the help of two tutors. The tutors were not assigned to a particular group; rather they went around the groups. This was to enable every group to benefit from every tutor's experiences. For confidentiality, all the participants' real names were replaced with pseudonyms.

\section{Research Procedure}

The PBL writing process was conducted in two cycles, each cycle lasted for 3 weeks. In each of the cycle, the participants were given an ill-structured problem to collaboratively discuss and propose viable and plausible solutions to the problems. In the first week, the participants are presented with an Ill-structured problem. One of them read the problem and together they discussed and clarified unclear terms in the problem to ensure that every one of them understood the problem. That would ease the discussion and allow them to propose the solution. Thereafter, they brainstormed and generated ideas related to the problem. They hypothesised various causes and possible solutions to the ill-structured problem. Further, the participants identified learning issues, which are things they needed to find more information to enable them to propose the solutions, from their hypothesis. Having identified the learning issues, they shared the issues among them to enable carrying out mini research or self-study to find out the needed information. At the end of the discussion, every member took home a topic for self-directed learning.

In the second week, the participants exchanged their findings of self-directed learning. They criticised the content and source of every information to ensure its validity and reliability. Thereafter, they wrote the first draft of their proposed solutions to the ill-structured problem. While drafting the solutions, some groups identified further learning issues and shared them for selfdirected learning at the end of the meeting.

In the third week, every group presented its findings to the class where the received feedback from other groups and the tutors. Following the class presentation, the participants edited and redrafted their writing and finally submitted to the tutors.

In between the first and the second PBL cycles, a debriefing session was conducted with the tutor and the participants. In the session, they discussed issues related to the PBL approach and writing. This was to clear some of the participants' misconceptions, correct their mistakes and to enable them to participate well in the second PBL cycle. 
The participants worked collaboratively brainstormed and generated possible solutions under the guidance of the tutors. They also identified learning issues which are things they needed to conduct a self-study to gather available information related to the problem.

\section{Instruments}

Audio- and video-recorders were used to collect the data for the study. The participants' interactions during the PBL writing process were captured and transcribed verbatim. Two illstructured problems were given to the participants. The first ill-structured problem was terrorism in Northern Nigeria which involved students. Some students were captured and kidnapped while other students joined the terrorist. Other students stopped attending schools or transferred their scholarship to other places in fear of the terrorist. The second ill-structured problem was about Nigerian undergraduates' excessive engagement with social media which negatively affected their academic performance. The participants were asked to collaborative discuss and propose viable and plausible solutions to the ill-structured problems.

\section{Findings and discussion}

In order to examine the strategies used by the tutors in facilitating the participants' learning in the PBL writing process, their interactions during the PBL processes were recorded and transcribed verbatim. Hmelo-Silver and Barrows (2006) model and Nguyen's (2013) model were used as the analytical framework. The findings of the study reveal that the tutors used various strategies to facilitate the participants' in the writing process. The following sections present and explain how the strategies were employed by the tutors. Actual samples from the transcripts are also presented to support the explanation.

\section{Open-ended questioning}

Open-ended questioning was the main strategy used by the tutors to facilitate the participants to achieve their writing goals in the PBL process. It was used by the tutors to help the participants to address most of the writing goals and to actively get involved in the interactions. In addition, using open-ended questioning made the participants think, reflecting on their previous experiences, and encourage them to give more explanations on some of the causes or solutions to the ill-structured problems. The tutors used open-ended questioning to support the participants throughout the PBL writing process, during planning, drafting, and reviewing processes. For instance, during the planning process, the tutors supported them to generate and organise ideas relevant to the illstructured problems and draw outlines of the writing. They also used open-ended questions to help the participants to identify suitable titles for their writing, determine the type of essay to write, and form a thesis statement.

For example, in Excerpt 1 the participants deliberated in order to get a suitable heading or title of the writing which captures the attention of a reader and summarised the content of the writing. The excerpt occurred while proposing solutions to the ill-structured problem of terrorism in Northern Nigeria. Habib suggested that their title should be 'terrorism and its consequences'. Sulaiman refuted that point out that it generalised the whole country while in the ill-structured problem it specified as university students in the Northern part of Nigeria. He referred to the ill-structured problem and suggested that the title should capture the ill-structured problem. The group agreed on the title of their writing to be 'terrorism in Northern universities: causes and solutions'.
Excerpt 1
Habib
: Ok let us just start writing. Our heading should be terrorism and its consequences. Right?
Tutor $\quad:$ How does it relate to the ill-structured problem?
Sulaiman : I think we are opening it to all because the problem is restricted to universities. So if you say terrorism where, in the whole country or at the level of university?
Justina $\quad:$ In university but in the whole country
Habib : In the northern part of the country, the problem mention terrorism and the issue of abduction.
Sulaiman : Let us read the problem again and see. It says "the recent attack 
and abduction of some university by some terrorist group and the involvement of some university students." I think the problem has to do with university students. I think it is restricted to university students because it makes some of students to transfer their studies to other safer universities while other students abandon studies completely.

Habib : What do you think should be the title?

Sulaiman : I think the title should also have relevance with students and universities. We are not mention only terrorism in the north, by this we are opening it to the whole north, the entire north

Habib : Yes, that will generalise while we have to specify.

Indo : So what do you suggest?

Sulaiman : What of 'terrorism in northern universities: causes and solutions' how do you see that?

Habib $\quad$ : For me I totally agree with this title 'terrorism in northern universities: causes and solutions' I think that is what the question ask us to do

Open-ended questioning was also used by the tutors to support the participants during the drafting process, the use of the open-ended question helped the participants to write suitable introductions to their writing, present and organise the ideas identified in the outline, ensure the connection between the ideas and write a suitable conclusion to their writing. For instance, in excerpt 2 the participants deliberated on how to conclude their essay. The excerpt occurred when they were proposing solutions to the problem of excessive engagement with social media by Nigerian undergraduates. With the help of a facilitator, the participants were able to write a conclusion to their writing. They agreed to summarise the causes and the solutions to the illstructured problems and call for an action, that is, what they expect their readers to do after reading their essay

$\begin{array}{ll}\text { Excerpt } 2 & \\ \text { Khadija } & \text { : How do we conclude the essay? } \\ \text { Ismail } & \text { : We can write, in conclusion } \\ \text { Tanko } & \text { : Khadija, give us your idea } \\ \text { Tutor } & \text { : What do you think you should write in the conclusion? } \\ \text { Khadija } & \text { : Summarise the cause and the solutions } \\ \text { Tutor } & \text { : Only that? Any other? } \\ \text { Jibril } & : \text { I think we can write... what we expect our reader to do } \\ \text { Tutor } & : \text { Like? } \\ \text { Khadija } & : \text { Ok, in conclusion, these are some of the causes and solutions of } \\ & \text { students' excessive engagement with social media... } \\ \text { Tutor } & : \text { Is there anyone with a different idea? } \\ \text { Jibril } & : \text { We can say these, according to our findings and ideas } \\ \text { Ismail } & : \text { We can conclude by saying these are only some of the causes and } \\ & \text { solutions to the problem. Them we mention the solutions... } \\ \text { Khadija } & : \text { A reader knows these are part of the causes not all }\end{array}$

During the reviewing process, the tutors also used open-ended questioning to support the participants. For example, it was used to allow the participants to edit their writing by correcting the title, content, organisation, grammatical mistakes, spellings, and choice of words and expressions of the writing. Excerpt 3 is an example of how the tutors used open-ended questioning in the reviewing process. The excerpt occurred just before the participants began reviewing their writing. The participants set guidelines on how to edit their writing. They mentioned that they could look at the purpose and content of their writing reviewing the writing. They mentioned it as content or the central message of their writing while group three did not mention it. The following shows how group two set their editing criteria.

\section{Excerpt 3}

Facilitator : So, when editing what do you look at?

Ibrahim : We look at the content. 


$\begin{array}{ll}\begin{array}{l}\text { Facilitator } \\ \text { Ibrahim }\end{array} & \begin{array}{l}\text { : What do you mean by looking at the content? } \\ \text { To make sure everything is inserted. We do not leave anything } \\ \text { behind. }\end{array} \\ \text { Facilitator } & \begin{array}{l}: \text { Is that what you understand by content? } \\ \text { Samuel }\end{array} \\ \text { Ibrahim } & \begin{array}{l}\text { The cons, the central message you are writing } \\ \text { something that will not answer the question, }\end{array}\end{array}$

As mentioned earlier, open-ended questioning is the main strategy used by the tutors in supporting the participants' learning in the PBL writing process. Other strategies such as pushing for explanation and summarising points were in a form of open-ended questioning. For instance, in excerpt 1 the participants were discussing the ill-structured problem of terrorism in Northern Nigeria. Ismail mentioned religious bigotry as one of the causes of terrorism in the country. The tutor used opened-ended questioning to push Ismail to give an explanation on the concept of religious bigotry as a cause of terrorism in Northern Nigeria. That made Ismail think and explain the concept of religious bigotry based on his understanding. The tutor did not evaluate Ismail's explanation or add any information but pushed him further to think of the causes of religious bigotry. From the explanation, Ismail identified causes such as improper teaching of religious doctrines, and what should be done to stop it.

\section{Excerpt 4 \\ Tutor}

Ismail

Tutor

Ismail

Tutor

Khadija

Jibril
: Ismail, can you shade light, what do you mean by religious bigotry?

: by religious bigotry, I mean (...) religious intolerance. That means this people that called Boko Haram, they go terrorizing and killing people, you know they claim that they want to establish what, sharia. To my understanding throughout history you will never find people that established sharia through this kind of terrorist activities. So they are killing Muslim and non-Muslim. Those that do not follow them, those that do not believe in their ideology the kill them, whether they are Muslim or Christians. And in their area where they captured, they are trying kill all people there. That is why I said religious intolerance.

: Ok, what are the causes of religious bigotry?

: Improper teaching of religious doctrines. The real thing is not taught. For example, if it's an Islamic sect that is involved in this. It is about jihad may be, they misunderstand jihad and think jihad means killing people while jihad means resistance. Someone is trying to impose something that is not comfortable with your religion and is forcing you to, so you defend yourself, or strive to maybe better one's self. So if that is what they are doing, but now they take jihad for killing people or forcing people to joint one's religion. So I think misunderstanding of religious concepts is what leads to extremism.

: You mentioned improper teaching of religious doctrines how, who do you think is responsible for the teaching?

: We have many people who can be responsible. First, it should be from the parents. They can teach religion right from the home. We also have schools, maybe Islamic schools. And even the western schools also, we have subjects like Islamic studies. They can teach them. And I believe it will be better

: Yeah... I have point to... I mean I have something to add on the point as far as religious extremism is concerned. Government should also assist or try to stop this religious extremism by establishing ministry of religious affairs in Nigeria, so as to monitor the activities of the clerics and what they teach and the 
err..., individual mosques and churches. So this should also be the way to solve the menace.

Pushing of explanation here helped the participants to explain and think of more causes and viable solutions to the ill-structured problem. It also helped them to identify their knowledge limitation. From the excerpt, it could be seen that from Ismail explanation, Khadija and Jibril thought of other ideas and offered some solutions. This finding has confirmed that of Hmelo-Silver \& Barrows (2006) which showed that pushing for explanations encourages the students to realise their knowledge limitation, identify learning issues and eventually become self-reliant for direction while looking for information during the self-directed learning.

\section{Re-voicing}

At a point during the discussion, the tutors restated or repeated what the participants said to help the participants to explain possible causes and viable solutions to the ill-structured problems. Revoicing was also used by the tutor to explain or confirm some possible causes or solutions to the illstructured problem suggested by some of the participants. In doing so, the causes or the solutions were marked as important and eventually influenced the direction of a discussion. In other instances, re-voicing was used by the tutors to keep the discussion on track as in excerpt 2 .

In the excerpt, the participants were discussing some of the factors that made Nigerian undergraduate excessively engage with social media. Yunus mentioned that undergraduates engaged with social media excessively because the nature of their study was uninteresting. The tutor asked other participants to give more explanation on why the study was uninteresting. However, it seemed Abubakar did not understand that because he only repeated what Yunus said. There, the tutor restated what Yunus said to the group. The restatement helped to keep learning on track as the tutor affirmed what Yunus said. This kept the discussion alive and subtly influenced its direction as Ishaq made a further contribution to support what Yunus said. Re-voicing also encouraged the participants to agree and build on one idea at a time.

\section{Excerpt 2}

Tutor

Yunus

Tutor

Abubakar

Tutor

Abubakar
: So, what do you mean by uninteresting?

: I mean the style, the study style or the mode of schooling is not very interesting. You sit down for two hours confined in a hall that is not very conducive while one is explaining things. Well, it may be interesting but there is social media which more interesting than the other one. And people tend to like things that are more interesting than those interesting. So social media affects our studies because it is more interesting than our studies. If now our school will be more interesting than the social media may be we would like it more than the social media

: Any other factor to add to what Yunus has said?

: I think we have to agree with what he said because it is what is happening all the day sometimes you may be unwillingly in the class rather than willingly. So whenever you turn on your cell phone you may be seeing things that are of interest to you. Even in the newspapers connected, twitter, Facebook and all other social media sites or platforms you may get something of interest that divert your attention from learning to your personal interest

: Yunus said that learning is uninteresting. So, why uninteresting because you are confined in an unconducive classroom for two hours, and students are not involved in the learning process. These are some reasons. So do you have other causes to add?

: Umm...

\section{Summarising points}

Another strategy used by the tutors to facilitate the participants' learning is summarising the points made by the participants. The tutors used to summarise points made by the participants during the PBL writing process in order to make the discussion progress and make all the participants 
involved in the discussions. In Excerpt 3 the participants were discussing the problem of terrorism in Northern Nigeria and then identified some possible solutions to the problem. The discussion got stalled, as they could not think of other viable solutions. The tutor asked Yunus to summarise the possible solutions the group identified so far. Thereafter, the tutor asked the participants if they had anything to add to the summary. By doing so, he was able to involve all the participants in the discussion. Also, he was able to make the group lively and encouraged the participants to think of more possible solutions to the problem of terrorism in Northern Nigeria.

\section{Excerpt 3 \\ Tutor}

Yunus

Tutor

Yunus
: From the discussion, you have identified many reasons why students get involved in terrorism and various measures to be taking in order to stop them. Can you summarise to the group.

: We have talked about them all, that is, public awareness or awareness campaigns. We want people to be security conscious, we want people to send their children to school, we want people to satisfy the needs of their children we want people to know ah ---, we want the government to watch the border, we want government to create jobs, we want the international community to understand the situation and help and so on. This can be by publicizing the real situation and even in terms of educating people, there should be public awareness campaign to make people aware of their problem and how to solve them.

: How can you achieve all these?

: We can do this things by maybe publishing articles in newspapers, having posters and billboards that will motivate people and inspire them regarding peaceful living, and I think this will also help solve, promoting all the solutions we have proposed.

\section{Following the PBL Routine}

Other strategies the tutors used to facilitate the participants learning were through following the PBL steps. In the structure of the PBL process, white-board is used by the students to record their groups' activities. The board is normally divided into four columns. In the first column, the hypotheses which are the possible causes and possible solutions to the ill-structured problem are written. Other information gathered about the ill-structured problem are recorded in the second column. Learning issues, which are a list of information to be pursued during self-directed learning, are recorded in the third column. In the fourth one, actions to be taken by the students to solve the problems are recorded (Hmelo-Silver, 2004). Therefore, the tutors encouraged and supported the participants to generate and evaluate the hypothesis, identify learning issues and wrote them down on the cardboard paper.

\section{Generating/Evaluating Hypothesis}

Having drawn the coulombs on the cardboard paper, the tutors to ask the participants to generate or evaluate the hypothesis. While planning their writing, the tutors encouraged the participants to use their prior knowledge and hypothesise the causes and the solutions to the ill-structured problems. This helped the participant to have focus in their discussion and become more aware of limitations in their knowledge. It also helped the participants to improve effective reasoning as well as keep the learning process in progress. Without generating a hypothesis, the participants would have engaged in an unfocused discussion and data collection during self-directed learning. This could be seen in excerpt 4 when the participants were discussing the problem of terrorism in Northern Nigeria.

\section{Excerpt 4}

Tutor

: What do you think are the causes of the insecurity in Northern Nigeria?

Ummi : Poverty is one of the problems that brings this problem

Tutor : How does poverty cause this problem?

Ummi : Poverty leads children or people to involve them into this kind of 
Tutor

Yunus

Tutor

Yunus problem because; if they don't have money they will do anything to get it in order to um, um, to solve their problem.

: What do you think should be done?

: Well, I think I have a point too, (...) religious extremism

: How can religious extremism cause terrorism?

: You know there are people who hold religion, well we can't say too seriously, even though the major problem is that they misunderstand some religious concepts like the jihad and they feel that if you do not belong to their religion or their sect, well you must be forced to join and that causes the trouble, and the major problem we are facing in the northern region that causes the killing and the abduction is the problem of book haram which is a form of religious extremism. So I think it is also one of the causes.

In the excerpt, the tutor encouraged them to think and hypothesise some possible causes and possible solutions to the problem. For instance, Ummi hypothesised that poverty is one of the causes of terrorism in Northern Nigeria. Yunus also hypothesised that religious extremism is another factor that caused terrorism in the country. Generating hypothesis helped to generate more discussions among the participants, as everyone had to explain why his /her hypothesis was made. From the explanations, other participants made their contributions. This also helped the participants to identify their knowledge limitations and write them as learning issues. This is in line with Hmelo-Silver and Barrows (2006) who pointed out that encouraging the students to generate hypotheses helps to keep the learning process on track. It also helps students to focus their inquiry and become aware of the limitations of their knowledge.

\section{Creating Learning Issues}

Learning issues are things students want to get more information about to enable them propose viable solutions to the ill-structured problem in the PBL process. Therefore, tutors helped the participants to create learning issues from their discussions in order to accomplish their writing goals. For example, the tutors helped the participants to identify things they had limited knowledge about and encouraged them to conduct self-directed learning and find more information on the items. The self-directed learning gave the participants opportunities to learn and acquire more information to fully support their hypothesis on the possible causes and solutions to the ill-structured problems. The process where the tutors encouraged the participants to create learning issues is demonstrated in excerpt 5 where the participants identified ignorance as another cause of terrorism in Northern Nigerian.

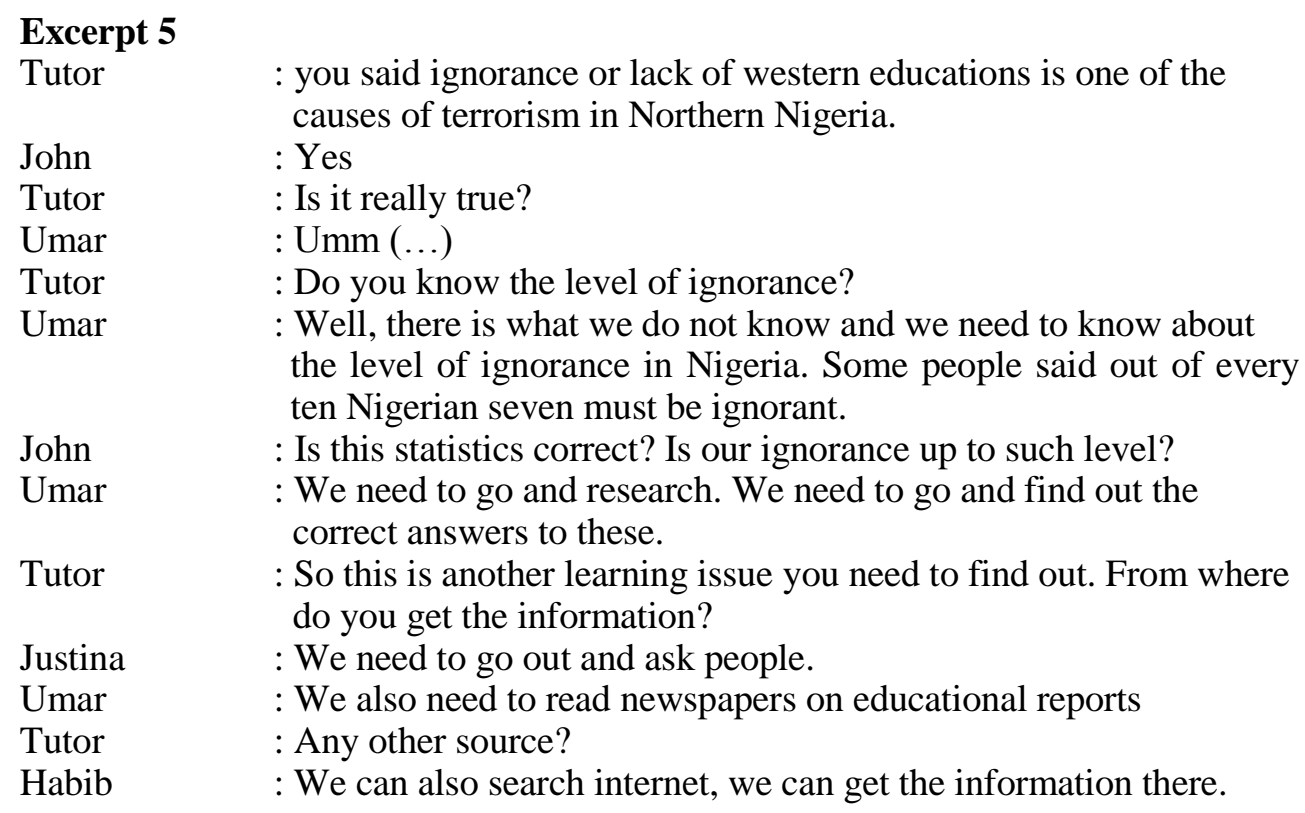


As could be seen in excerpt 5, the participants only identified ignorance as one of the factors behind terrorism in the region. However, they did not know the level or extent of the ignorance to support the claim. The tutor helped them to realise this as their knowledge gap and classified it under learning issues. The tutor also helped them to identify the source from which to obtain more information on it. This has confirmed the findings of Hmelo-Silver \& Barrows (2006), which show that creating learning issues helps students to identify gaps in their knowledge and to have opportunities to learn in order to meet their knowledge needs through self-directed learning. While generating hypothesis and identifying the learning issues as described previously, the tutors asked the participants to write down all the group activities on the cardboard paper for record purposes.

\section{Writing down points on cardboard paper}

The tutors, therefore, encouraged the participants to use the cardboard papers to record all their activities. On various instances, the tutors asked the participants to either write down a point on the cardboard or refer to the already written points for elaboration. This helped to keep the learning process on track. It also helped to ensure that all ideas were recorded and important ideas were not lost or skipped. The process also allowed the participants to evaluate their performance. This agrees with Hmelo-Silver and Barrows (2006) which suggested that writing down points on whiteboard helps to ensure that all ideas are recorded and important ideas are not lost and to evaluate their learning and performance. It also helps to keep the students' learning process on track. Excerpt 6 is an example of where a tutor asked the participants to use the cardboard paper to record their ideas.

Excerpt 6
Ummi
Tutor
Ummi
Ishaq

: Improper home-training... It also brings terrorism.

: You can write it down on the cardboard paper. $=$

$:=\mathrm{Ok}$

Ishaq $\quad:$ Should we say improper home-training brings this problem? How does improper home-training cause this problem?

In the excerpt, the tutor asked Ummi who was the scribe of her group to write down points on the cardboard paper so as not forget or skip any point.

\section{Using Politeness}

The use of politeness by the tutors to facilitate students' learning in the PBL process is a strategy identified in this study which differs from Hmelo-Silver and Barrows (2006) findings. Throughout the PBL process, the tutors politely supported and encouraged participants to participate actively in the PBL writing process. For example, the manner in which the tutors spoke to the participants was polite. In addition, the tutors called every participant by his/her name. In some case, the tutors added a title to the participants' name such as 'Malam' (Mr) or Malama (Miss/Mrs). This helped in building rapport between the tutors and the participants because these are signs of respect and politeness in the participants' culture, the strategy increased the participants' self-efficacy and allowed them to get involved in the interaction as they had a sense of belonging. It also helped in avoiding conflict or unnecessary disagreement among the participants during the process. Using politeness is in line with Nguyen' (2013) affective support. She describes affective support as any support given to learners during collaborative learning to make them endure and engage with a given task; build rapport with fellow learners; motivate and build confidence, and have a sense of safety and success during the learning process.

\section{Conclusion}

From the discussion so far, it is revealed that the PBL that the tutors used various strategies to facilitate the participants' writing process in the PBL environments which helped the students to achieve their various writing goals during the process. Theoretically, the findings of the study extend the PBL approach from medical school (where it originated) to ESL writing classroom. The findings also corroborate the constructivism theory that through social interaction students worked collaboratively with the support of the tutors to achieve their writing goals. The students were able to build new knowledge and develop their cognitive abilities based on their previous knowledge and tutor support. 
Pedagogically, the study provides teachers with a new method of teaching writing, particularly in the Nigerian context. This study shows that PBL is an approach is contrary to the traditional teachercentred method used by many Nigerian instructors where students are left to write individually and unassisted (Muodumogu \& Unwaha, 2013; Omachonu, 2003). Therefore, the study creates teachers' awareness of the need to engage and support students during the writing process. Also, it informs the teachers on the need to use real-life simulation as a writing topic in the writing process.

\section{References}

Hmelo-silver, C. E., Barrows, \& Barrows, H. S. (2006). Goals and strategies of a problem-based learning facilitator. Interdisciplinary Journal of Problem-based Learning 1(1), 21-39.

Hmelo-Silver, C. E. (2004). Problem-based learning: what and how do students learn? Educational Psychology Review, 16(3), 235-266.

Mardziah H. Abdullah. (1998). Problem-based learning in language instruction : A constructivist model. ERIC Clearinghouse on Reading English and Communication Bloomington, 1-6.

Mardziah H. Abdullah, \& Tan, B. H. (2008). Wired together: Collaborative problem-pased language learning in an online forum. Malaysia Journal of ELT Research 4, 54-71.

Nguyen, M. H. (2013). EFL students' reflections on peer scaffolding in making a collaborative oral presentation. English Language Teaching, 6(4), 64-74.

Santrock, J.W. (2005). Psychology (7th edition). Boston: McGraw-Hill.

Santrock, J. W. (2009). Educational psychology (4th Edition). London: Mc Graw- Hill.

Tan, O. S. (2004) Students' experiences in problem-based learning: Three blind mice episode or educational innovation? Innovations in Education and Teaching International, 41(2), 169-184.

Raymond, E. (2000). Cognitive characteristics. In M. A. Allyn \& A. Bacon, Learners with mild disabilities (pp. 169-201). Needham Heights, Pearson Education Company.

Savin-Baden, M. (2000). Problem-based learning in higher education: Untold stories. Buckingham: Open University Press.

$\mathrm{Su}$, Y., (2007). The Impact of scaffolding type and prior knowledge in a hypermedia, problembased learning environment. Unpublished Ph.D. thesis, Arizona State University.

Vygotsky L. S. (1978). Mind in society: The development of higher psychological

processes. Cambridge, M. A: Harvard University Press. 